\title{
EXPLORING READING SKILLS' INSTRUCTION IN COMPULSORY ENGLISH COURSE - A CASE STUDY OF PUBLIC COLLEGE
}

\author{
Tahira Musavi \\ Assistant Professor, \\ Department of English, D. J. Sindh Govt. Science College, \\ Sindh, Pakistan \\ Email: ta14hr@gmail.com
}

\section{Sajida Zaki}

Professor,

Department of Humanities, NED University of Engineering \& Technology,

Sindh, Pakistan

Email: drzaki@neduet.edu.pk

\section{Mehwish Arif}

Lecturer,

Department of Humanities, NED University of Engineering \& Technology,

Sindh, Pakistan

Email: mahwisharif@neduet.edu.pk

\begin{abstract}
The present study explores the reading instruction at grade-XII at a public college in Karachi to capture the reading instruction practices in compulsory English course. Using case study method involving interviews with teachers followed by observations of their reading classes an in-depth study was planned that attempted to give a holistic picture of the reading instructional practices. The teachers' classroom practices were also interpreted in the light of the analyzed curriculum and text book being followed. The findings indicate a missed opportunity since no meaningful outcomes can be envisaged as a result of the conventional, content based and examination oriented classroom pedagogy adopted by teachers in their reading classes. The interview and classroom observation data contradicted indicating the teachers' claims differed drastically from their actual classroom practices. This study reconfirms earlier studies and suggests several policy and pedagogical implications for education department, college administrators, English language teachers and teacher educators.
\end{abstract}

\section{KEYWORDS}

Reading Instruction, public college, compulsory English, reading skills, strategies, second language classroom, ESL 
INTRODUCTION

English is a compulsory subject taught at public colleges as part of the curriculum prescribed for high school certificate requirement. It is already a second language in Pakistan used for official communication and as the medium of instruction and education. English language proficiency is also a major requirement for securing admission at professional universities since English is an integral part of all placement tests. The need for proficiency in English Language is already established with the place it has attained globally as the medium for acquiring, creating and sharing knowledge and as the means for communication across continents and cultures between individuals connected through variegated forms for different purposes (Jimenez \& Rose, 2010; Paik, 2008). Despite, tremendous global spread of English language and its resulting impact, the teaching and learning of English Language in non-native settings leaves a lot more to be achieved in order for the learners to really develop their language skills viz, listening, speaking, reading and writing (Dar, Kazmi \& Zaki, 2010; Sultana \& Zaki, 2015; Zaki \& Dar, 2012). Pakistan is a second language setting with reference to English Language and its teaching-learning in the formal academic setting has been adequately studied to reveal several problems including outdated curriculum and ineffective pedagogy (Rahman, 2002; Sultana \& Zaki, 2015; Warsi, 2004). The teachers and learners have been found to approach English as a content-based subject requiring mastery of curriculum material for passing examinations rather than a language that involves development of skills for life-long application (Sultana \& Zaki, 2015).

English language teaching and learning is stretched throughout academic years that is right from elementary school to bachelor's education in the local education setting. Though, studies report that students did not develop competence required for performance in the target language (Dar et al., 2010; Zaki \& Dar, 2010; Shamim, 2008; Sultana \& Zaki, 2015). A study by Mari, Pathan and Shahriar (2011) carried out with one hundred university students reported that the students experienced anxiety while communicating in English. This study reconfirmed the assertions made in an earlier study by Dar et al. (2010) about learners lacking oral language skills despite long exposure to formal English language learning within academic environments. Writing skills being deficient, cramming and plagiarism as resulting consequences have been stressed in numerous studies establishing the need for a fresh perspective on the real outcomes and achievements at the end of the prolonged English language teaching learning (Arifa, 2009; Haider, 2012; Rahman, 2002; Zaki, 2010). These studies implicitly provide insights about the skills students may have attained in developing the remaining two language skills, listening and reading, as a result of the same outmoded and ineffective language instruction. Maqbool (2002) reported in her study that school children with good reading skills had better self-concept as compared to poor readers. This also echoes the reading as literacy perspective that emphasizes on 
developing students reading skills for a far reaching impact of education. Drawing inspiration from these studies, this paper outlines an empirical study that explores the reading skills instruction in compulsory English classes at a public college. This study is significant as English language is the official language and the language of education implying that reading skills intervention is primarily targeted in English classrooms only. It is assumed that all English compulsory curses and teachers make adequate provision for reading instruction aimed at developing students reading skills for future academic and life situations. The rationale for initiating such a research that captures precisely the reading instruction is also based on the extensive literature calling for educators to enable learners to read and enhance reading instruction. One such conviction comes from Allington (2002), "enhanced reading proficiency rests largely on the capacity of classroom teachers to provide expert, exemplary reading instruction" (p.1); and also the passionate plea made by Afflerbach, Pearson \& Paris (2008), "Reading researchers, perhaps now more than ever before, have a responsibility to use the most relevant research to bridge theory and practice with coherent and useful models of reading development, curricula, instruction, and assessment" (p.1).

\section{Focus \& need for the study}

Reading instruction heavily rests with the teachers who take up teaching and developing students reading skills by aligning their instructional plans with the developments in the research in reading. The local educational context including the language classrooms is characterized by traditional teaching-learning practices, dearth of skillful language teachers coupled with predictable examination questions and availability of ready-made notes induce rote memorization of content. Even the elitist and the best colleges and institutes have not been spared by the rampant practices that interfere with any attempt to impart quality education. These ubiquitous practices have taken away the motivation and interest among teachers and students to spend efforts in developing reading skills. This situation becomes a bigger challenge when the students advance into bachelor study programmes wherein their academic performance is affected owing to a lack of adequate reading skills development. This ultimately makes our students, who join graduate research programme, face tremendous difficulties in fulfilling the demands of advanced academic reading and writing tasks that constitute a major activity of research. There is a need to explore the reading instruction as a first step towards improving reading pedagogy that generates outcomes in the form of students reading abilities. Existing contextual studies, similar to those cited in the opening section of the paper, have only implied towards inadequate second language reading skills as a result of conventional language pedagogy and other related problems. There are no detailed studies explicitly undertaken to probe the reading instructional practices within mainstream academic settings. This study fills the research gap by investigating reading instructional practices through interviews with language teachers and classroom observations. The data obtained from these diverse 
sources will lead to mirror more comprehensively the actual practices related to formal reading instruction in order to fulfill the primary aim of this study which is to explore reading instruction practices at public colleges in compulsory ESL classrooms in terms of the objectives and outcomes identified and subsequently the classroom procedures and protocols that are carried out by ELTs to promote ESL learners reading skills.

\section{LITERATURE REVIEW}

Reading instruction remains a neglected aspect of second language teaching as a result students are unable to perform in all other subjects since reading skills and strategies are transferred to all other subjects on the curriculum and are not restricted to language classrooms only. This thought resonates with what a review of reading research suggests that there is a strong correlation between academic success and achievement and students who learn to read early and easily (Duncan et al., 2007; Butler, Urrutia, Buenger, \& Hunt, 2010). Students reading success is also linked with life-long learning (Hill \& Crevola, 2001). Reading is linked with the development of thought and an individual's capacity to think critically. Teaching reading has received stimulated attention from all stakeholders agreeing to its importance and impact (Afflerbach, et al., 2008). Earlier reading instruction was emphasized for school children, but its importance is recognized for all grades. Read-aloud, where a teacher reads the text to the students, is a prominent strategy to teach young learners to read though educators associate this more suited to elementary education (Marchessault \& Larwin,2013; Wolsey, Lapp, \& Dow, 2010) as evident from the statement by Hodges (2011), "Although reading aloud with children is widely agreed to be beneficial, it is often assumed both by teachers and young people themselves that it is something you grow out of as you become an increasingly proficient reader" (p. 19). There is a raised concern about literacy education and a declining habit of reading among adolescent students and youth (NCTE, 2012). Reading research and literature from several decades' reveal reading as directly linked with an individual's knowledge and skills. Effective reading skills and learning reading strategies enable students to acquire more domain information and comprehend better. This in turn make them confident in using the skills and strategies acquired through reading instruction resulting in a more conscious application in different academic, professional and personal contexts and for a variety of purposes. Grabe (2009) identifies six purposes of reading within academic settings: searching for information; developing quick understanding; learning; integrating information; evaluate, critique and use information; and for general comprehension.

The academic tasks at college vary widely across disciplines in nature and functions; and students are expected to engage and interpret text of increasing difficulty (Eckert, 2011). This academic challenge becomes routine with the development of students reading skills through reading instruction. Anderson and Pearson (1984) described 
reading instruction as facilitating comprehension by modifying existing knowledge or creating new knowledge as students read texts. Conley (1992) suggests a corresponding definition in which reading instruction is seen as the interplay that teachers actively create between texts and students through which students learn. Simply put, reading instruction may be interpreted as the imparting of guidelines to students so as to facilitate them to comprehend the text material with ease and simultaneously creates interest in the reading activity as well as the reading texts. Reading instruction should be a continuous activity across all educational levels since beside being an important skills enabling students to gain new information it also helps learners in acquiring new language skills (Holschuh and Paulson, 2013; Verlag, 2009). Reading is considered to be a multifaceted process of constructing meaning from written texts involving dynamic interaction among reader's existing knowledge, the information suggested in the reading text and the context of the reading situation. It is a complex skill requiring the coordination of a number of interrelated sources of information (Anderson et al., 1985; Wixson et al., 1987). Reading instruction has evolved over the last many decades owing to three major theories that are briefly described here to provide the theoretical reference against which the reading instruction in the local set-up will be compared. Traditional View is based on Behaviourism of the 1950s and is also termed as bottom-up, and outside -in processing models. This theory is focused on the printed form of the text and the learners are taught sub-skills that are hierarchically ordered and applying these readers comprehend the texts. This view sees reading as a receptive skill with readers passively decoding printed meaning that is present in the reading text. The emphasis on the language features such as phonics, vocabulary and reproduction of meaning that are the principal characteristics of this view were later criticised as its main deficiencies (Dole et al., 1991; McCarthy, 1999; Nunan, 1991; Pardede, 2006). Cognitive View emerged as an alternative psycholinguistic model of reading that attempted to address the limitations of the Traditional View. This opposing view interprets reading as a topdown processing and incorporates schema theory, and sees reader as the focus of the reading activity who is actively uses schemata and strategies while interacting with the text to process and construct meaning (Dole et al. 1991; Dubin \& Bycina, 1991; Nunan 1991;Paran, 1996; Rumelhart, 1977; Tierney and Pearson, 1994). Block in 1992 suggested meta-cognitive view as a closure on the ongoing debate between bottomup, linguistic- based processing model of Traditional View and the top-down, knowledge or schema- based Cognitive View. Meta-cognitive view involves thinking about what one does while reading and this implies that the emphasis in this view is on strategic reading. Metacognition attempts to focus on the control readers execute on their ability to comprehend a text before, during and after reading through strategies like identifying the purpose and type of the text as well as its character, features; establishing author's purpose for writing the text; making predictions about what will come next by linking information gained earlier and the prior knowledge; and 
skimming, scanning or reading in detail ( Block, 192; Pardede, 2006; Klien et al., 1992; Vaezi, 2006). The reading skills and strategies suggested under these three reading theories and the resulting research and literature are summarized in Table 1. Reading instruction revolves around the classroom reading lessons developed around certain techniques that the teachers identify for the reading tasks and processes which enables students to apply different reading skills as they read.

Table 1: Reading skills \& strategies

\section{Reading Skills \& Strategies}

- Previewing (reviewing titles/ headings/images to sense the structure/ content of the reading text)

- Skimming (reading to get at the gist of text)

- Scanning (reading to look for specific piece of information)

- Predicting (text type, purpose, writing style, vocabulary, content, discourse structure)

- Word-attack skills (tackling unfamiliar lexical items by using morphology, inference from text, etc., or by using a dictionary)

- Text-attack skills (the process of interpreting the text as a whole, using all the clues available including cohesion and rhetorical structure)

- Comprehension skills (it includes those skills that enables the reader to understand and apply the written material)

- Intensive reading (reading for detail)

- Extensive reading (reading for pleasure)

- Paraphrasing (restating the information and ideas in the text to check comprehension)

Reading skills are described roughly as a cognitive ability which a person is able to use when interacting with written texts. They are seen as a part of the generalized reading process. The teacher in the classroom imparts reading instructions with the purpose of developing and reinforcing reading skills and sub skills in students so that they can read more quickly and effectively. Afflerbach, Pearson, and Paris (2008) suggested that strategies are deliberate and goal-directed. In other words, students must consciously decide to employ a particular strategy in order to construct meaning from a text. Effective language instructors show students how they can adjust their reading behavior to deal with a variety of situations, types of input, and reading purposes. They help students develop a set of reading strategies and match appropriate strategies to each reading situation. Considering the complex nature of reading and the effort required in meaningfully developing reading literacy, reading can best be taught by dividing it into its component skills. There are five components of reading instruction: phonemic awareness, phonics, fluency, vocabulary, and text comprehension (NRP \& 
IRA, 2002). Reading is not a simple process, but a complex, multi-component skill that involves an intricate combination of many lower- and higher-level cognitive, linguistic, and non-linguistic skills and sub-skills (Nassaji 2014). Shanahan, Fisher \& Frey (2012) asserted that reading instructors' primary objective is to prepare students for dealing with text complexity instead of focusing on discrete skills. Pressley (2001) concluded that comprehension strategies instruction improves comprehension. In short, teaching and learning of reading skills in English is a highly technical, thoughtful, and planned activity and unless the process is handled bearing the research developments, the reading skills cannot be developed in an appropriate manner.

\section{RESEARCH QUESTIONS}

1. What are the Reading objectives and outcomes outlined in the prescribed curriculum and text books? Are there any guidelines provided for the teachers to plan reading instruction?

2. What are the teachers' reading instructional practices and awareness?

\section{RESEARCH METHODOLOGY}

This exploratory study uses case study method and the pragmatist paradigm to collect qualitative data at a public college in Karachi in order to answer the posed research questions. The selection of the college as a case in this study was made on two reasons. First, the access and convenience of data collection that involved interviews with teachers and observations of their reading classes which meets the requirement of a case study method that the in depth data may be gathered in the real context using a wide range of methods (Best \& James, 2005; Kumar, 2008; Yin, 2013). Second, the college is a prestigious and leading institute that has a remarkable history that is spread over about a century, and has had prominent academics and students affiliated with it.

It is assumed that unlike many other colleges there is likely to be better academic environment and practices prevailing at this college. This will meet the basic assumption of the case study methodology that the selected case for study is typical of cases to which through intensive analysis the findings may be generalized (Kumar, 2008). For data collection, all teachers (T1-4) who were teaching Compulsory English course to classes XII were interviewed following which each teacher's reading classes were observed twice. This ensured reliability of the research and its findings. The study was limited to XII only since it is assumed that being the terminal year of school education and the high-stakes exam year for university placement of the students the reading teaching-learning seriousness and motivation would allow valuable insights into the reading instruction practices.

Since the public colleges in Karachi that offer High School Certificate (HSC), also referred to as intermediate education levels corresponding to high school grades XI 
and XII, are registered with the sate-owned academic body the Board of Intermediate Education Karachi, therefore, these colleges are mandated to teach the prescribed syllabus of English. The students are then required to sit in the state- held- exams organized under the auspices of the same body to claim their High school certificate. Therefore in order to answer the first research question the prescribed curriculum and the text book (for prose section) were analyzed using the document analysis method (Corbin \& Strauss, 2008) to identify textual information or description on reading objectives, outcomes, and reading instruction guidelines for teachers especially related with the skills and tasks to be focused during instruction.

For the second research question teachers were interviewed and later their classes were observed using semi structured interview protocol and classroom observation checklist. For both these data collection activities prior consent was obtained and they were briefed about the study objectives, and were assured of complete anonymity and confidentiality. Since the researchers belonged to the same public education system and the small English language teaching community, the trust and comfort level already existed between the investigators and the teacher- participants. During classroom observation care was exerted not to interfere in the teaching -learning routine, and to remain silent observer.

\section{FINDINGS \& DISCUSSION}

The data collected from the analysis of documents (curriculum and text book), teachers-interviews, and classroom observations were analyzed thematically. The themes were derived from the review of literature and en masse explained the on-going reading instruction. The major themes include reading objectives and purposes, reading skills and strategies, underlying approach/view about reading instruction. The findings and interpretation of the analyses are presented below, and have been organized under the two questions raised in this study.

Q1. What are the Reading objectives and outcomes outlined in the prescribed curriculum and the text book? Are there any guidelines provided for the teachers to plan reading instruction? What reading skills are identified to be targeted as part of the reading instruction?

The document analyses of curriculum and the text book are carried out around four themes: reading objectives and outcomes, reading skills and strategies targeted, guidelines for reading instruction, reading activities or tasks to be focused during reading instruction. The most notable finding of curriculum document analysis is that it neither outlines the reading objectives nor outcomes. The document is also silent about the reading skills, sub skills or strategies that are aimed for compulsory English at XII college level. There are no provisions for the teachers with respect to any information or recommendation for suitable reading pedagogy, reading tasks and 
activities, and classroom procedures to be adopted for targeting reading skills.

These findings endorse the observations about English Language Teaching in Pakistan which is still an activity undertaken using a traditional and content- based approach since the curriculum document merely outlines the content areas and the prescribed texts to be covered as part of Compulsory English course. A similar pattern was observed in the findings derived from the analysis of the text book (see. Table 2). The plan of the text book reading units is again a very typical pattern observed in the conventional books used for language teaching and that is a reading text comprising several passages followed by a list of comprehension questions. The analysis of questions/ reading tasks (also presented in Table No. 2) reveals strong tendency for literal level comprehension questions, and very little opportunity for students to practice and develop advanced comprehension skills.

\section{Table 2: Document Analyses Findings}

\begin{tabular}{|c|c|c|}
\hline $\begin{array}{l}\text { Themes } \\
\text { for } \\
\text { Analyses }\end{array}$ & $\begin{array}{c}\text { Curriculum } \\
\text { (Document) } \\
\text { Analysis } \\
\text { Observations }\end{array}$ & $\begin{array}{l}\text { Text Book (Document) Analysis } \\
\text { Observations }\end{array}$ \\
\hline $\begin{array}{l}\text { Reading } \\
\text { Objectives } \\
\text { and } \\
\text { Outcomes }\end{array}$ & Not given & Not given \\
\hline $\begin{array}{l}\text { Skills/ } \\
\text { Sub skills/ } \\
\text { Strategies } \\
\text { to be } \\
\text { targeted }\end{array}$ & Not mentioned & Not mentioned \\
\hline $\begin{array}{l}\text { Reading } \\
\text { instruction } \\
\text { guidelines }\end{array}$ & Not included & Not included \\
\hline $\begin{array}{l}\text { Reading } \\
\text { Activities/ } \\
\text { tasks }\end{array}$ & Not mentioned & $\begin{array}{l}\text { Only post reading stage activities/tasks included in } \\
\text { the form of comprehension questions classified } \\
\text { around the comprehension levels (Literal level, } \\
60 \% \text {, Interpretive level } 25 \% \text { Evaluative level 15\%) } \\
\text { and reading skills (skimming, predicting, } \\
\text { summarizing, paraphrasing, predicting, vocabulary } \\
\text { skills) }\end{array}$ \\
\hline
\end{tabular}

Q 2. What are the teachers' reading instructional practices and awareness? In order to answer this question, the transcribed interview data and classroom 
observation sheets were analyzed against the themes in the questions that appeared on the interview and classroom observation protocols. These findings are separately presented in Tables 3 and 4.

Table 3: Findings of Teachers Interviews

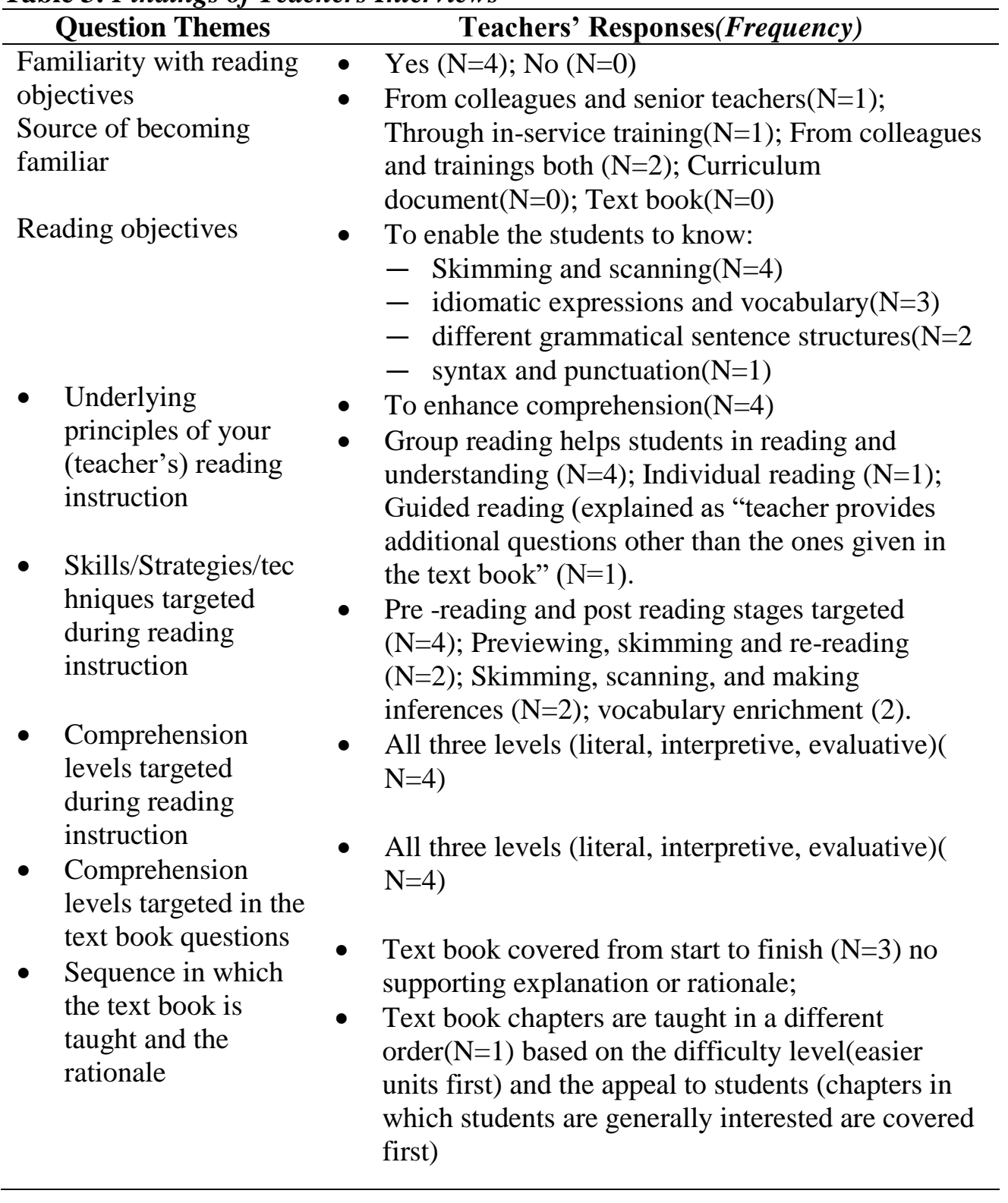


- Development of further reading tasks and activities
- $\quad$ Pre reading activities (brainstorming)

developed( $\mathrm{N}=2)$

While reading activities(short questions, true /false , MCQs) developed) $(\mathrm{N}=2)$

Post reading activities developed( $\mathrm{N}=4)$ [long questions asking personal critique of the reading text $(\mathrm{N}=2)$, summarize $(\mathrm{N}=2)$, Paragraph/essay $(\mathrm{N}=2), 3-4$ lines opinion $(\mathrm{N}=1)$

Despite strong assertion of the teachers, the findings presented in Table 3 reveal rudimentary awareness about the reading instruction and somewhat haphazard manner in which this gets translated as part of their classroom instruction. It is interesting to note that the data confirm all teachers having undergone in-service teacher training in reading from prominent teacher education organizations (such as SPELT, AKU, PACC) which is an attractive and regular feature of being associated with public education. Also, the findings of the second question-theme about the source that led to their awareness about reading objectives further establish that reading objectives are neither included in the curriculum nor in the text book (see Table 1) as indicated by the frequencies $(\mathrm{N}=0)$ in Table 3 . An interesting revelation of the interview data is teachers' satisfaction with the reading instruction and their confidence in helping students develop their reading skills.

The findings of classroom observations in Table 4 endorse the inference drawn from the interview data that reading instruction happens in a disorganized way. It lacks focus, structure and progression essential for developing reading skills in students. Combining the findings of tables 4 and 5 , the pattern of reading classes is quite obviously establishing the preference for the Traditional View of reading (Dole et al., 1991; McCarthy, 1999; Nunan 1991; Pardede, 2006). This finding also endorses previous studies that suggested the local English language teaching scenario leaves much to be attained as compared to what it achieves (Dar, Kazmi \& Zaki, 2010; Sultana \& Zaki, 2015; Zaki \& Dar, 2012).

Table 4: Findings of Classroom Observations (based on pre-defined Reading Instruction Themes)

\begin{tabular}{lll}
\hline \multicolumn{1}{c}{ Observation Themes } & \multicolumn{1}{c}{ Findings (Frequency) } \\
\hline Reading objectives & $\bullet$ & Neither mentioned nor targeted $(\mathrm{N}=4)$ \\
Reading Stages and the & $\bullet$ & Pre- reading: $\mathrm{Yes}(\mathrm{N}=4), \mathrm{No}(\mathrm{N}=0)$ \\
activities that happened & $\begin{array}{l}\text { Brainstorming using questioning based on the title } \\
\text { of the reading text } \\
\text { While- reading: } \mathrm{Yes}(\mathrm{N}=4), \mathrm{No}(\mathrm{N}=0) \\
\\
\text { Teacher provided students a list of words and }\end{array}$ \\
\hline
\end{tabular}




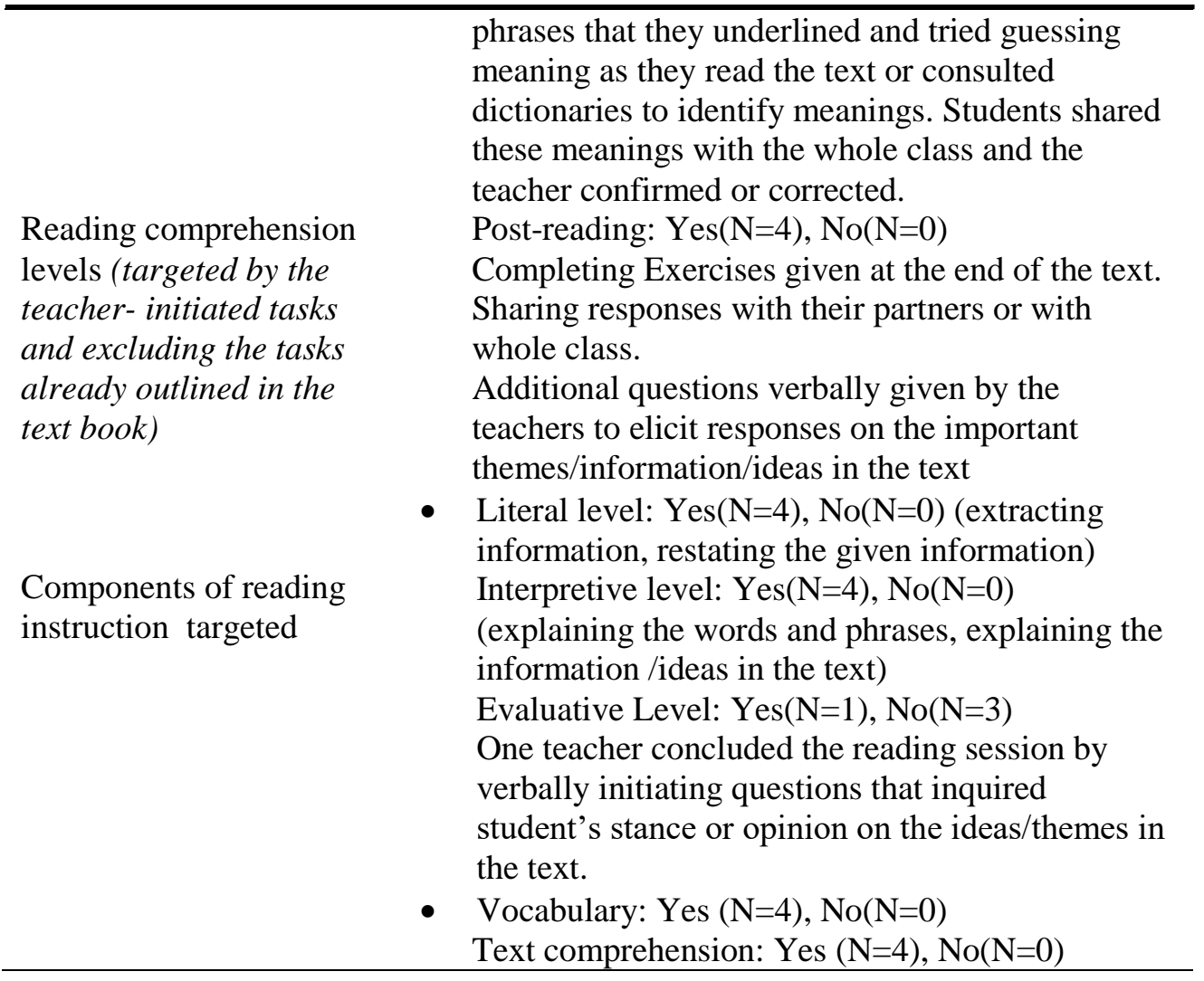

The recurrence of typical patterns of instructions across all four teachers' classrooms strongly supports the prevalence of a conventional language teaching methodology at the institute. Contrary to their claims made during the interviews(see Table 3), the observed classrooms did not reveal teachers targeting reading objectives, reading stages, three levels of comprehension, different skills and strategies. Though this reference does indirectly reveal some basic awareness about the reading instruction framework probably attained from the in-service teacher training they had received. But instead of implementing the acquired knowledge and skills, the teachers appear to have succumbed to the prevailing old instructional patterns. This calls attention to the need for some follow- up or monitoring mechanism to be introduced that may force teachers to implement what they have learnt for inducing a positive impact. The classroom observations also provided additional observations other than those made against the predefined themes (see table.5). These observations are presented in table 6. 
Table No.7: Additional Observation of reading classrooms and implication Observations Implications

- Unplanned questioning(oral) used at different points in time

- Ts' summary at the start of the lesson and explanations as the reading of the text progressed.

- The reading texts being lengthy Ts selected paragraphs/parts from the different sections of the text including texts based on narration or a historical account.

- The selected parts of the text were read (aloud) by the Ts and selected $\mathbf{S s}$ taking turns followed by explanation which is very occasionally interrupted by Ss' questions

- Ts remained the focus of all activity throughout class time and Ss were largely passive.

- Ss' reading (aloud) and questioning revealed difficulties with fluency.

- Besides the book and the chalkboard, no other teaching-learning aids were used.

- Ts did not suggest any further reading (related to the author or text theme or text format) to strengthen $\mathbf{S s}$ ' reading interest and skills further.
- Activities initiated by Ts were random and lacked adequate planning and specific purpose

- Eliminated the Ss' curiosity and the interest in reading the text.

- The cognitive and metacognitive processes could not be targeted.

- There is a rare chance that all Ss present were involved in reading. Other than a few Ss, passivity prevails.

- Traditional lecture -based, teacher -led class with Ss having limited or no opportunities for learning.

- Ss have reading difficulties and these are going unchecked still.

- While reading -stage is completely missed as this would require development of worksheets having tasks for Ss to attempt as they read. Ts are not planning reading instruction.

- Reading instruction remains focused on the completion of textbook and the curriculum with examination focus rather than development of reading skills and habit for life

\section{Ts: Teachers; Ss: Students}

A notable observation is regarding the use of reading aloud strategy with college students which negates the agreement of educators about this being more appropriate for elementary and primary school students (Hodges, 2011; Marchessault \& Larwin, 
2013; Wolsey, Lapp, \& Dow, 2010). This observation together with other observations about lack of planning and a complete disconnect with the framework of reading instruction are clear indicators about the local reading instruction practices.

\section{CONCLUSION}

This study was attempted with the intention of mapping the reading skills instruction at public colleges through in depth study of a single college to provide estimation of the extent to which development of students' reading skills is being targeted. Prior to collection of data from teachers using one -on- one interview and classroom observation strategies, the curriculum document and prescribed text book analyses for directions and details pertaining ongoing-reading instruction was completed. Unfortunately, the problems identified with the classroom reading practices are all linked with the base documents being silent about the current developments in field of English Language teaching in general and for reading skill in particular. All formal academic interventions emerge from the curricular guidelines which are then translated through the text books and formalized by the teaching-learning routines. The current study provides evidence that there is a need to revamp the existing curriculum and text book as the starting points for reforms in the local ELT. Consistent with the contextual studies (Dar, Kazmi \& Zaki, 2010; Sultana \& Zaki, 2015; Rahman, 2002;; Warsi, 2004; Zaki \& Dar, 2012), English language teaching is still happening under the conventional pedagogy. Communicative approach and language-skills focus is missing in the existing language instruction. The reading practices, as reported by the findings of the interview and classroom observation, confirms that Compulsory English is viewed as another content based subject instead of a language. Hence, reading instruction stressed on enabling students to know the content given in the text to be able to retain for examination which clearly deviates from the way reading instruction is explained in earlier works (Anderson \& Pearson, 1984; Conley, 1992; Nassaji, 2014). A significant conclusion of the study is the over-all status of English language teaching along with reading pedagogy at an urban elitist college which raises questions towards the English Language teaching apparently happening in other colleges within non urban and disadvantaged socio economic settings. Also, the fact that despite adequate in service teacher education the teachers continue teaching through the old-fashioned ways and ignore their responsibility towards their students in not preparing them to brace the future language challenges, and towards the education department in not enabling them to induce desired academic changes through teacher development. The findings of the study carry implications for the teachers, college students, and university placement offices about the deficient reading abilities that students will carry forward to their next academic level ultimately affecting their academic achievement. Implications are also evidently seen for the education department and for in-service teacher educators to plan further reading instruction and more importantly 
its implementation in the actual classrooms so these steps create the impact on the same lines as demanded by Allington (2002) and Afflerback et al. (2008).

\section{RECOMMENDATIONS}

The findings of the study recommended the following:

1. Curriculum should mention explicitly students' reading skills development which is necessary for academic achievement at colleges and subsequently in University.

2. After curriculum, teacher training is also necessary to focus on second language reading instructions.

3. Reading instruction focusing on reading skills and strategies planned, systematic instruction need to be imbedded in the education system of Pakistan as reading skills are prerequisites for writing and speaking skills. If students fail at reading, they would face failure in writing as well. Therefore, for academic success and later in careers, students need to be equipped with systematic reading skills.

\section{REFERENCES}

Afflerbach, P., Pearson, P. D., \& Paris, S. G. (2008). Clarifying differences between reading skills and reading strategies. The Reading Teacher, 61(5), 364-373.

Allington, R. L. (2002). What I've learned about effective reading instruction. Phi Delta Kappan, 83(10), 740-747.

Anderson, R. C., \& Pearson, P. D. (1984). A schema-theoretic view of basic processes in reading comprehension. Handbook of reading research, 1, 255-291.

Arifa, R. (2009). College teachers' perceptions of ELT: Relevance to teacher training, in Mansoor, S, Sikandar, A, Hussain, N, \& Ahsan N. M. (eds.) Emerging Issues in TEFL Challenges for Asia, Oxford: Oxford University Press.

Bacon, M. (1983). What Adult Literacy Teachers need to Know about Strategies for Focusing on Reading Comprehension? Lifelong Learning: The Adult Years, 6(6), 4-5.

Best, J.W. \& James, V.K. (2005). Qualitative Research. Ninth (Ed.) Research in Education. India: Pearson Education.

Block, E. L. (1992). See how they read: comprehension monitoring of L1 and L2 readers. TESOL Quarterly 26(2)

Butler, S., Urrutia, K., Buenger, A., \& Hunt, M. (2010). A review of the current research on comprehension instruction.

Conley, M.W. (1997).Content Reading Instruction: A Communication Approach. New York: Mc Grow-Hill

Corbin, J. \& Strauss, A. (2008). Basics of qualitative research: Techniques and procedures for developing grounded theory (3rd Ed.). Thousand Oaks, CA: Sage

Dar, M.F., Zaki, S. \& Kazmi, H.H. (2010). Students' reactions regarding the use of process strategy for oral presentations in ESP. English Language and Literary Forum, 12, 15-30.

Dole, J.A., Duffy, G.G., Roehler, L.R., \& Pearson, P.D. (1991). Moving from the Old to the 
New: Research on Reading Comprehension Instruction. Review of Educational Research, 61(12), 239-264.

Dubin, F., and Bycina, D. (1991). Models of the process of reading. In Celce-Murcia (ed.), Teaching English as a Second or Foreign Language. Boston, Mass.: Heinle and Heinle.

Duncan, G. J., Dowsett, C. J., Claessens, A., Magnuson, K., Huston, A. C., Klebanov, P., \& Sexton, H. (2007). School readiness and later achievement. Developmental psychology, 43(6), 1428.

Eckert, L. S. (2011). Bridging the pedagogical gap: Intersections between literary and reading theories in secondary and postsecondary literacy instruction. Journal of Adolescent \& Adult Literacy, 52(2), 110-118.

Grabe, W. (1991). Current Developments in Second language Reading Research. TESOL Quarterly, 25(3), 375-406.

Grabe, William. Reading in a second language: Moving from theory to practice. Ernst Klett Sprachen, 2009.

Haider, G. (2012). Process approach in writing: Issues and implications for teaching in Pakistan. International Journal of Humanities and Social Science, 2(2), 147-150.

Hill, P., \& Crévola, C. (2001). Children's literacy success strategy: An overview (Revised ed.). Melbourne: Catholic Education Office.

Hodges, G. C. (2011). Textual drama: the value of reading aloud. English Drama Media, 19, 19-26.

Holschuh, J.P., \& Paulson, E.J. (2013). The Terrain of College Developmental Reading. Texas State University: CRLA.

Jimenez, R. T. \& Rose, B. C. (2010).Knowing how to know: building meaningful relationships through instruction that meets the needs of students learning English. Journal of Teacher Education, 61(5) 403-412.

Kumar, R. (2008). Selecting a Study Design. Second(ed.). Research Methodology p.113. India: Pearson Education.

Maqbool, E. (2002). Relationship between self-concept and achievement among reading and non-reading disabled school children (Doctoral dissertation, Institute of clinical psychology University of Karachi Karachi-Pakistan a thesis submitted in partial fulfillment of the requirements for the degree of doctor of philosophy in the faculty of arts, institute of clinical psychology, University of Karachi).

Mari, M., Pathan, H., \& Shahriar, A. (2011). Willingness to communicate in L2: A perception of Pakistani university students. ELF Annual Research Journal, 13, 65-82.

Marchessault, J. K., \& Larwin, K. H. (2013). Structured Read-Aloud In Middle School: The Potential Impact On Reading Achievement. Contemporary Issues in Education Research (Online), 6(2), 241.

McCarthy, C. (1999). Reading Theory as a Microcosm of the Four Skills. Applied Linguistics Series.

Nassaji, H. (2014). The role and importance of lower-level processes in second language reading.Lang.Teach.47.1, 1-37.

National Reading Panel (US), \& International Reading Association. (2002).Evidence-based reading instruction: Putting the National Reading Panel report into practice. International Reading Assoc. 
NCTE (2012). Reading Instruction for all students: A policy research brief produced by the National Council for Teachers of English. Retrieved on 25 January 2015 http://www.ncte.org/library/NCTEFiles/Resources/Journals/CC/0221sep2012/Chron0221PolicyBrief.pdf

Nunan, D. (1991). Language Teaching Methodology. Hertfordshire: Prentice Hall International.

Oxford, R. L. (1990). Language Learning Strategies: What Every Teacher Should Know. New York: Newbury House Publishers.

Paik, J. (2008). "Learning English, imagining global": The narratives of early English education experiences in South Korea. The International Journal of Learning, 15(10), 71-78.

Palincsar, A.S., \& Brown, A. L. (1984). Reciprocal Teaching of Comprehension-fostering and Comprehension-monitoring Activities. Cognition and Instruction, 1, pp.117-175.

PAN, L. (2009). Sub skills Approach and Extensive Approach to Reading in TEFL. Journal of Cambridge Studies, 4(3), 112-117.

Paran, A. (1996). Reading in EFL: facts and fiction. ELT Journal 50

Pardede, P. (2006). A Review on Reading Theories and its Implication to the Teaching of Reading. UKI: ELT'n Edu A cyber ELT \& Edu service from Universitas Kristen Indonesia [online].

Pearson, P.D. (1985). Changing the Face of reading Comprehension Instruction. The Reading Teacher, 38(8), 726-737.

Rahman, T. (2002). Language, ideology, and power: Language learning among the Muslims of Pakistan and North India, Oxford: Oxford University Press.

Robinson, H.A. (1977). Teaching Reading and Study Strategies: The Content Area. London: Allyn \& Bacon.

Robinson, H.A., Faraone, V., Hittleman, D. R., \& Unrah, E., (1990) .Reading Comprehension Instruction 1783-1987: A Review of Trends and Research New York: International Reading Association.

Rumelhart, D. E. (1977). Toward an interactive model of reading. In S. Dornic (ed.), Attention and Performance IV. New York, NY: AcademicPress.

Samuels, S. J., and M. L. Kamil. 1988. "Models of the Reading Process." In Carrell, Devine, and Eskey, eds. 1988. 22-36.

Shamim, F. (2008). Trends, issues and challenges in English language education in Pakistan. Asia Pacific Journal of Education, 28(3), 235-249.

Shanahan, T., Fisher, D., \& Frey, N. (2012). The challenge of challenging text. Educational Leadership, 69(6), 58-62.

Sultana, M., \& Zaki, S. (2015). Proposing Project Based Learning as an alternative to traditional ELT pedagogy at public colleges in Pakistan. International Journal for Lesson and Learning Studies, 4(2), 155-173.

Tierney, R. J., and P. D. Pearson. (1994). Learning to learn from text: A Framework for Improving Classroom Practice. In Rudell, Ruddell, and Singer, eds. 1994. 496-513.

Vaezi, S. (2006). Theories of reading. Teaching English. Publication of British Council. London.

Warsi, J. (2004). Conditions under which English is taught in Pakistan: An applied linguistic perspective. Sarid Journal, 1(1), 1-9. 
PJER, Vol 4, Issue 1 (2021) Exploring reading skill's ...

Wixson, K. K., Peters, C. W., Weber, E. M., \& Roeber, E. D. (1987). New directions in statewide reading assessment. The Reading Teacher, 40(8), 749-754.

Wolsey, T.D., Lapp, D., \& Dow, B. (2010). Reading practices in elementary schools: format of tasks teachers assign. Journal of Research and Innovative Thinking, 3(1), 105-116.

Yin, R. K. (2013). Case study research: Design and methods. Sage publications.

Zaki, S. (2010). Enhancing Students' Learning Through 3-Tier Self Evaluation Model: Successful Implementation at a public sector Engineering University" Fifth International Forum on Engineering Education (IFEE2010) - Quality. Globalization and Local Relevance- Jointly with the European SDPROMO II Conference Sustainable Development in Higher Education, 23-25 November 2010, University of Sharjah, United Arab Emirates. Proceedings (CD \& Book) ISBN:9948-10-092-1

Zaki, S. \& Dar, M.F. (2012). Reflections on the local ELT context: The teaching learning objectives and the obstacles. English Language and Literary Forum,14, 1-12. 